\title{
Dysfunctional pulmonary artery conduit and co-existing large pseudoaneurysm: well-suited for a percutaneous approach with the Melody valve?
}

\author{
Rouven Kubicki', Brigitte Stiller and Jochen Grohmann
}

\begin{abstract}
Pseudoaneurysm formation is a rare but potentially life-threatening complication after surgical repair of congenital heart disease. We present a boy with truncus arteriosus communis 14 years after homograft placement in pulmonary position. On follow-up, he presented progressive chronic homograft degeneration. Moreover, a large pseudoaneurysm in the right ventricular outflow tract was surprisingly depicted. We opted for a two-stage interventional approach.
\end{abstract}

Keywords: Pseudoaneurysm, Right ventricular outflow tract conduit, Percutaneous pulmonary valve implantation, Two-stage interventional approach, Homograft degeneration

\section{Background}

Pseudoaneurysm of the right ventricular outflow tract (RVOT) is a rare complication after surgery for congenital heart disease. A substantial number of patients are asymptomatic, however, compared to true aneurysms, pseudoaneurysms are presumed to be high risk regarding life-threatening complications due to rupture or compression of adjacent mediastinal structures. Once diagnosed, pseudoaneurysms should be treated either by surgery, or via an interventional approach (Antal et al. 2010; Levine et al. 1995; Masri et al. 2014; Sadiq et al. 1994; Yeo et al. 1998).

We report on a two-stage interventional approach for valve replacement in a degenerated right ventricular-topulmonary artery (RV-PA) homograft by percutaneous pulmonary valve implantation (PPVI) and exclusion of a large co-existing pseudoaneurysm.
*Correspondence: rouven.kubicki@universitaets-herzzentrum.de Department of Congenital Heart Defects and Pediatric Cardiology, Heart Center, University of Freiburg, Mathildenstraße 1,79106 Freiburg, Germany

\section{Case presentation}

A 14-year-old boy with type A1 truncus arteriosus communis underwent Rastelli repair with a $16 \mathrm{~mm}$ RV-PA homograft at 6 weeks of age. He developed very well, presenting no signs of heart failure over the following years. Echocardiography showed progressive chronic homograft degeneration with moderate to severe stenosis and insufficiency. Moreover, transthoracic echocardiography unexpectedly depicted a pseudoaneurysm on followup (Additional file 1: Video S1). Cardiac MRI revealed a pulmonary regurgitant fraction of $50 \%$, end-diastolic volume of $134 \mathrm{ml} / \mathrm{m}^{2}$, dilation of the non-calcified homograft up to $18-24 \mathrm{~mm}$, and a large pseudoaneurysm distal to the homograft's valve (Additional file 2: Figure S1). This aneurysm had a short neck with a narrow ostium. Neither the patient's history nor clinical findings suggested any infective etiology (e.g., endocarditis). Following interdisciplinary discussion, we opted for an interventional approach.

Initial hemodynamic assessments confirmed elevated right ventricular (RV) pressure up to roughly $3 / 4$ systemic (RV 92/0-12 $\mathrm{mmHg}$ ). The RVOT angiogram revealed the nearly non-calcified homograft with an elastic appearance and its narrowest diameter measuring around 
$10 \mathrm{~mm}$ exactly on the valve's level. The lumen of the rounded-shaped pseudoaneurysm measured around $20 \mathrm{~mm}$. Its $5 \mathrm{~mm}$ neck was closed with an Amplatzer ${ }^{\mathrm{TM}}$ Duct Occluder (ADO II 6-4 mm; St. Jude Medical, St. Paul, MN) (Fig. 1a, b).

Next step was to create a landing zone for PPVI. Due to the compliant nature of the whole conduit, test-ballooning revealed only dynamic (muscular) proximal notching towards the RVOT, and a little notching while ballooning the distal conduit (Additional file 3: Video S2). Thus, as the pseudoaneurysm appeared effectively excluded, we decided against a long, covered stent, and chose a bare pre-stent with an open-cell design to provide sufficient anchoring (AS XXL $30 \mathrm{~mm}$; Andramed, Reutlingen, Germany) crimped on a $24 / 40$ mm Balloon-in-Balloon ${ }^{\circledR}$ system (NuMed, Hopkinton, NY, USA), and implanted it in the distal conduit overlapping most of the Amplatzer ${ }^{\mathrm{TM}}$ Duct Occluder II (Fig. 1c). Control angiography revealed free insufficiency without extravasation of any contrast. RV-pressure had dropped to $46 / 0-9 \mathrm{mmHg}$ at the end of the procedure.
To minimize the risk of any device embolization, PPVI was scheduled 2 months later with the aim of ensuring the prestent's stability while assuming some endothelial tissue ingrowth from the distal (native) pulmonary artery (Fig. 2). To reinforce the proximal landing zone, we implanted two more pre-stents (AS XXL 39 mm; Andramed, Reutlingen, Germany) before subsequently implanting the Melody valve via the $22 \mathrm{~mm}$ ensemble (Medtronic, Medtronic, Minneapolis, USA), followed by a final redilation with a $25 / 50 \mathrm{~mm}$ Cristal balloon achieving optimal fitting (Balt, Montmorency, France). The final angiogram showed an excellent outcome without any endoleak/aneurysmal formation. Final hemodynamic assessment demonstrated significant improvement and normal RV pressure. These findings remained stable during 3 year follow-up. There is no echocardiographic evidence of the valve's mechanical dysfunction.

\section{Discussion}

Pseudoaneurysms are a rare but potentially life-threatening complication after RVOT surgery. Factors implicated in their etiology are increased right ventricular pressure
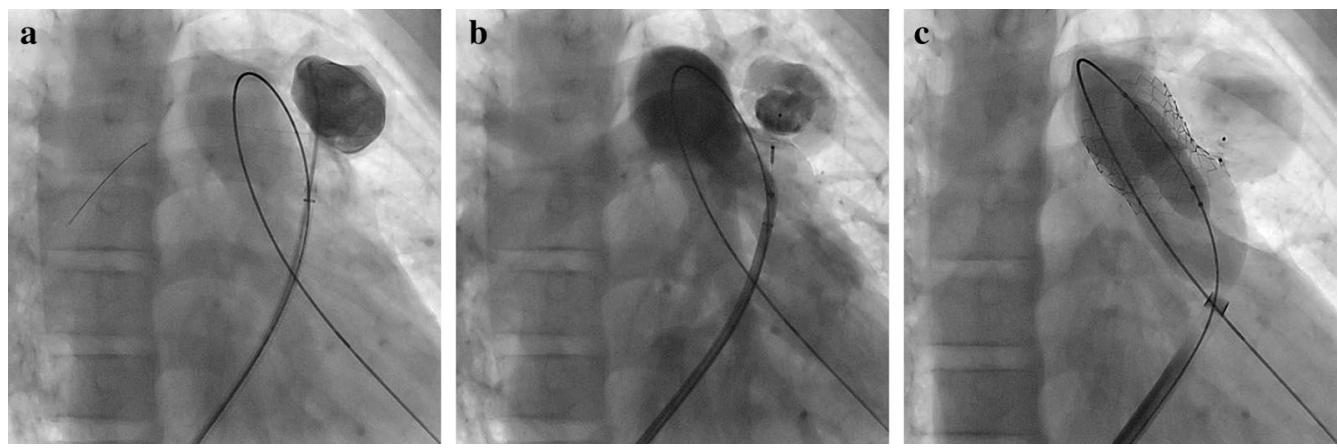

Fig. 1 Guided by a wire-supported 8 French long sheath, the rounded-shaped pseudoaneurysm was entered via a 4 French endhole-catheter with a floppy 0.014 inch coronary wire (a). Its lumen and neck measured around 20 and $5 \mathrm{~mm}$. Control angiography before Amplatzer ${ }^{\mathrm{TM}}$ Duct Occluder $\|$ 6-4 mm release, which was delivered via the corresponding 5 French TorqVue ${ }^{\mathrm{TM}}$ system $(\mathbf{b})$. Implantation of the first pre-stent (c)
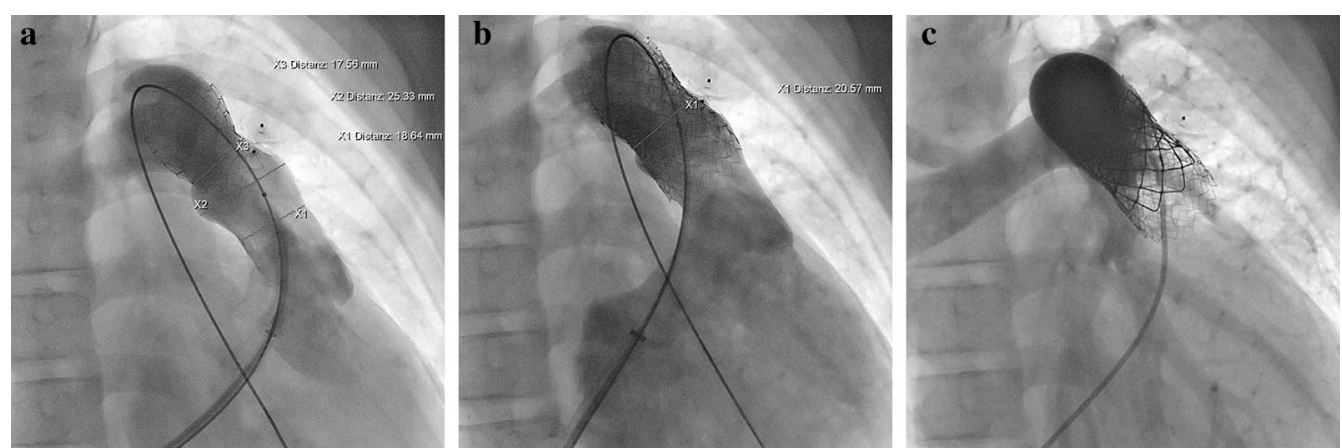

Fig. 2 Re-catheterization revealing excluded pseudoaneurysm and stable pre-stent position (a). Well prepared landing-zone after implantation of two more pre-stents $(\mathbf{b})$. Final result after percutaneous pulmonary valve implantation (c) 
leading to mechanical strain at the suture line, the suture technique and materials, local infection, trauma, and significant pulmonary regurgitation (Levine et al. 1995; Sadiq et al. 1994). Considering the tendency for pseudoaneurysms to become progressively larger and risk rupturing, further treatment is needed (Antal et al. 2010; Levine et al. 1995). In most patients, the pseudoaneurysm can be resected under cardiopulmonary bypass on a beating heart. Surgery can be carried out safely with low mortality and morbidity, and is considered the mainstay treatment (Yeo et al. 1998; Murashita et al. 2002). On the other hand, as the pseudoaneurysm originates from the right ventricular outflow tract and lies just behind the sternum, there is the risk of bisecting during sternotomy. Thus, device occlusion may be considered an alternative in certain patients, particularly as percutaneous treatment of a dysfunctional right ventricular outflow tract has emerged as a recognized alternative as well, including techniques that may extend the use of PPVI beyond its current indications (Cools et al. 2015; Feltes et al. 2011; Holzer and Hijazi 2016; Jagia et al. 2011; Vaidyanathan et al. 2004). Another word of caution is needed when discussing pseudoaneurysms, however, as they actually carry a high risk of rupture. An underlying abscess/endocarditis must be considered a contraindication for any interventional approach.

In our case we decided on transcatheter two-stage approach, which included closing the pseudoaneurysm's entrance with the Amplatzer device, followed by preparing the very compliant conduit for later PPVI. We were skeptical about the safety and durability of a long covered stent, as it might have carried a higher risk for stent migration and fracture via continuous mechanical (muscular) RVOT stress. We used non-covered stents with open-cell design for pre-stenting to provide sufficient anchorage in the retention zone while avoiding possible migration during or after valved stent implantation. The final valve implantation proceeded uneventfully. To optimize the result by flaring the stent-edges, we redilated $2-3 \mathrm{~mm}$ with an oversized balloon, which is usually well tolerated to this extent due to the Melody valve's coaptation zone (Cheatham et al. 2013). Finally, we obtained a satisfactory result with adult-sized valve-diameters, thereby preserving the option for redo-intervention (valve-in-valve procedure) as a long-term solution.

\section{Conclusion}

Percutaneous-transvenous exclusion of a large RVOT pseudoaneurysm, followed by PPVI in a very compliant RV-PA homograft succeeded, thus reducing both the risk for sudden rupture and the number of cardiac surgeries in this patient's lifetime after a Rastelli procedure in early infancy.

\section{Additional files}

Additional file 1: Video S1. Large pseudoaneurysm depicted at the level of the proximal homograft with its short neck and ostium.

Additional file 2: Figure S1. Relationship between the pseudoaneurysm and the inner sternal table to highlight the risk of bisecting during sternotomy.

Additional file 3: Video S2. Test-ballooning revealed only a little notching while ballooning the distal conduit.

\section{Abbreviations}

RVOT: pseudoaneurysm of the right ventricular outflow tract; RV-PA: right ventricular-to-pulmonary artery; PPVI: percutaneous pulmonary valve implantation; RV: right ventricular.

\section{Authors' contributions}

RK clinical management of the case, and manuscript redaction and correction. BS and JG manuscript redaction and correction. All authors read and approved the final manuscript.

\section{Acknowledgements}

We thank Carole Cürten for language editing and Stefan Heinz for graphic design.

\section{Competing interests}

The authors declare that they have no competing interests.

\section{Consent}

The patient gave his consent for the use of his personal and medical information for the publication of this case report and any accompanying images.

\section{Ethical approval}

All procedures conducted in studies involving human participants concurred with the ethical standards of our institutional and/or national research committee and with the 1964 Helsinki declaration and its later amendments or comparable ethical standards.

\section{Financial support}

We received no specific grant from any funding agency, commercial or notfor-profit sectors to carry out this research.

Received: 2 January 2016 Accepted: 8 September 2016

Published online: 15 September 2016

\section{References}

Antal AD, Cikirikcioglu M, Myers PO, Didier D, Kalangos A (2010) Respiratory distress after surgery of RVOT pathologies: a word of caution on pseudoaneurysm development. Thorac Cardiovasc Surg 58(6):356-358

Cheatham SL, Holzer RJ, Chisolm JL, Cheatham JP (2013) The Medtronic Melody (R) transcatheter pulmonary valve implanted at 24-mm diameter-it works. Catheter Cardiovasc Interv 82(5):816-823

Cools B, Brown SC, Heying R et al (2015) Percutaneous pulmonary valve implantation for free pulmonary regurgitation following conduit-free surgery of the right ventricular outflow tract. Int J Cardiol 186:129-135

Feltes TF, Bacha E, Beekman RH 3rd et al (2011) Indications for cardiac catheterization and intervention in pediatric cardiac disease: a scientific statement from the American Heart Association. Circulation 123(22):2607-2652

Holzer RJ, Hijazi ZM (2016) Transcatheter pulmonary valve replacement: state of the art. Catheter Cardiovasc Interv 87(1):117-128

Jagia P, Sharma S, Juneja R, Guleria R (2011) Transcatheter treatment of pulmonary artery pseudoaneurysm using a PDA closure device. Diagn Interv Radiol 17(1):92-94 
Levine JC, Mayer JE Jr, Keane JF, Spevak PJ, Sanders SP (1995) Anastomotic pseudoaneurysm of the ventricle after homograft placement in children. Ann Thorac Surg 59(1):60-66

Masri SI, Majdalani MN, Bitar FF (2014) Novel percutaneous femoral arterialtransthoracic approach for closure of ascending aortic pseudoaneurysm with a septal occluder device in a child. Cardiol Young 24(4):752-755

Murashita T, Hatta E, Imamura M, Yasuda K (2002) Giant pseudoaneurysm of the right ventricular outflow tract after repair of truncus arteriosus: evaluation by MR imaging and surgical approach. Eur J Cardiothorac Surg 22(5):849-851
Sadiq M, Fenton AC, Firmin RK (1994) False aneurysm of the right ventricular outflow tract after total correction of tetralogy of Fallot: diagnosis by echocardiography and successful repair by neck cannulation for cardiopulmonary bypass. Br Heart J 71(6):566-568

Vaidyanathan B, Kannan BR, Kumar RK (2004) Images in cardiovascular medicine. Catheter closure of pseudoaneurysm of the main pulmonary artery. Circulation 110(13):e322-e323

Yeo TC, Malouf JF, Oh JK, Seward JB (1998) Clinical profile and outcome in 52 patients with cardiac pseudoaneurysm. Ann Intern Med 128(4):299-305

\section{Submit your manuscript to a SpringerOpen ${ }^{\odot}$ journal and benefit from:}

- Convenient online submission

- Rigorous peer review

- Immediate publication on acceptance

- Open access: articles freely available online

- High visibility within the field

- Retaining the copyright to your article 